\title{
Molecular characterization of hypothetical scaffolding-like protein S1 in multienzyme complex produced by Paenibacillus curdlanolyticus B-6
}

\author{
Patthra Pason ${ }^{1}$, Junjarus Sermsathanaswadi², Rattiya Waeonukul', Chakrit Tachaapaikoon', Sirilak Baramee ${ }^{1}$, \\ Khanok Ratanakhanokchai ${ }^{3}$ and Akihiko Kosugi ${ }^{4^{*}}$
}

\begin{abstract}
Paenibacillus curdlanolyticus B-6 produces an extracellular multienzyme complex containing a hypothetical scaffolding-like protein and several xylanases and cellulases. The largest (280-kDa) component protein, called S1, has cellulose-binding ability and xylanase activity, thus was considered to function like the scaffolding proteins found in cellulosomes. S1 consists of 863 amino acid residues with predicted molecular mass 91,029 Da and includes two $\mathrm{N}$-terminal surface layer homology (SLH) domains, but most of its sequence shows no homology with proteins of known function. Native S1 (nS1) was highly glycosylated. Purified nS1 and recombinant Xyn11A (rXyn11A) as a major xylanase subunit could assemble in a complex, but recombinant S1 (rS1) could not interact with rXyn11A, indicating that S1 glycosylation is necessary for assembly of the multienzyme complex. nS1 and rS1 showed weak, typical endoxylanase activity, even though they have no homology with known glycosyl hydrolase family enzymes. S1 and its SLH domains bound tightly to the peptide-glycan layer of P. curdlanolyticus B-6, microcrystalline cellulose, and insoluble xylan, indicating that the SLHs of S1 bind to carbohydrate polymers and the cell surface. When nS1 and rXyn11 A were co-incubated with birchwood xylan, the degradation ability was synergistically increased compared with that for each protein; however synergy was not observed for rS1 and rXynA. These results indicate that S1 may have a scaffolding protein-like function by interaction with enzyme subunits and polysaccharides through its glycosylated sites and SLH domains.
\end{abstract}

Keywords: Paenibacillus curdlanolyticus, Hypothetical protein, Surface layer homology domain, Xylanase, Multienzyme complex, Carbohydrate-binding domain

\section{Introduction}

Plant biomass, which has potential as a renewable resource, contains a complex mixture of polysaccharides, such as cellulose, hemicellulose (xylan and galactomannan), pectic substances (polysaccharides comprising mainly 1,4-linked $\alpha$-D-galactosyluronic acid such as galacturonan), other polysaccharides (e.g., fuco-xyloglucan)

\footnotetext{
*Correspondence: akosugi@affrc.go.jp

${ }^{4}$ Biological Resources and Post-harvest Division, Japan International Research Center for Agricultural Sciences (JIRCAS), 1-1 Ohwashi, Tsukuba, Ibaraki 305-8686, Japan

Full list of author information is available at the end of the article
}

(Caffall and Mohnen 2009), and lignin, which is a complex polymer of phenylpropane units. The efficient hydrolysis of these polysaccharides requires not only $\beta-1,4$-glycosidic chain-cleaving enzymes, such as endo- $\beta-1,4$-glucanase and $\beta$-glycosidase, but also the cooperation of other enzymes such as $\beta$-1,4-xylanases and side chain-cleaving enzymes like $\alpha$-L-arabinofuranosidase (Caffall and Mohnen 2009). The xylan-degrading enzymes have potential industrial and commercial applications in areas such as food engineering using xylooligosaccharides and cellulose pulping (Pauly and Keegstra 2010; Saha 2003).

A facultative anaerobic bacterium Paenibacillus curdlanolyticus B-6, isolated from an anaerobic digester fed 
pineapple waste, produces numerous cellulolytic/xylanolytic enzymes (Pason et al. 2006). P. curdlanolyticus B-6 also produces a cellulosome-like unique multienzyme complex system of at least 11 protein subunits associated in a $1450-\mathrm{kDa}$ complex by distinct cohesin-dockerin interactions (Pason et al. 2006). This extracellular complex is composed of a $280-\mathrm{kDa}$ scaffolding-like core protein (S1), several minor xylanases and cellulases, and major xylanases of $\sim 40 \mathrm{kDa}$ (Pason et al. 2010). Protein S1 of the multienzyme complex was isolated through four chromatographic steps and has a xylan-degrading ability (Pason et al. 2010).

S1 may assemble the multienzyme complex using a mechanism distinct from the cohesin-dockerin interactions of the cellulosome (Bayer et al. 2004, 2008; Demain et al. 2005; Doi and Kosugi 2004; Lynd et al. 2002), because the major xylanase subunit (Xyn11A) of the multienzyme complex does not have a dockerin domain-like structure that is necessary to bind the cohesin domains present in cellulosome scaffolding proteins (Pason et al. 2010; Sermsathanaswadi et al. 2014). In typical cellulosome-producing, anaerobic, cellulolytic bacteria (e.g., Hungateiclostridium thermocellum), the cellulosome $(2.0-3.5 \mathrm{MDa})$ consists of a large $(197 \mathrm{kDa})$, non-catalytic, multimodular scaffolding protein CipA, which includes nine cohesins, four hydrophilic modules, and a family 3 carbohydrate-binding module (CBM3). The enzymatic units are noncovalently assembled to the scaffolding protein through high-affinity type I interactions between the dockerin domains of the catalytic units and cohesins on the scaffold. S1 has a large molecular mass and a cellulose binding ability, and it forms a multienzyme complex, which is similar to that of known scaffolding proteins. Consequently, it would be interesting to determine whether the $\mathrm{S} 1$ protein acts as a scaffolding protein at the molecular level. In this study, we report the molecular characterization of the scaffolding-like protein S1 from a multienzyme complex produced by $P$. curdlanolyticus B-6.

\section{Materials and methods}

\section{Bacterial strains and culture medium}

Paenibacillus curdlanolyticus B-6 is in the Culture Collection of the National Center for Genetic Engineering and Biotechnology, Thailand (accession number BCC 11175). Strain B-6 was grown on Bergey's mineral salt medium ( $\mathrm{pH}$ 7.0) supplemented with birchwood xylan (Sigma-Aldrich, St. Louis, MO, USA) as previously reported (Pason et al. 2006, 2010). E. coli JM109 (TaKaRa Bio, Shiga, Japan), E. coli Rosetta $^{\mathrm{TM}} 2$ (DE3), E. coli BL21 (DE3) (Merck KGaA, Darmstadt, Germany), pET19b, and pET22b (Merck KGaA) served as cloning and expression hosts and protein expression vectors.

\section{Purification of $\mathrm{nS} 1$ protein from culture supernatant}

The multienzyme complex, including S1 protein, was purified from the cellulose-binding fraction of $P$. curdlanolyticus B-6 culture supernatant, as previously reported (Pason et al. 2006, 2010). To separate nS1 from the enzyme subunits, the purified multienzyme complex was incubated at $4{ }^{\circ} \mathrm{C}$ for $15 \mathrm{~h}$ in $1 \mathrm{M}$ sucrose and $5 \mathrm{mM}$ ethylenediaminetetraacetic acid. The nS1 was successfully isolated from the enzymatic subunits using Sephacryl S-500 HR gel filtration chromatography (GE Healthcare, Buckinghamshire, UK). The purity and molecular mass of $\mathrm{nS} 1(280 \mathrm{kDa})$ were confirmed by SDS-PAGE (ATTO, Tokyo, Japan), and the protein was concentrated using Amicon Ultra centrifugal filters (Merck Millipore Corp., Darmstadt, Germany).

\section{Isolation and DNA sequence analysis of $\mathrm{S} 1$}

To clone the gene encoding S1, N-terminal and internal amino acid sequences were determined from purified $\mathrm{S} 1$ protein. For $\mathrm{N}$-terminal amino acid sequencing, the S1 protein was subjected to SDS-PAGE and transferred onto a polyvinylidene difluoride membrane (Merck Millipore Corp.) using a Mini Trans-Blot ${ }^{\circledR}$ electrophoretic transfer cell (Bio-Rad Laboratories, Hercules, CA, USA). The protein bands were determined by staining with $0.1 \%$ Ponceau Red (Wako Pure Chemical, Osaka, Japan), and the protein on the membrane was sequenced using the Edman method (Thermo Fisher Scientific, MA, USA). For the internal amino acid sequencing of the S1 protein, the single $280-\mathrm{kDa}$ protein band was extracted from a polyacrylamide gel and digested with trypsin.

To clone the $S 1$ gene, mixed oligonucleotide primers were designed based on the deduced $\mathrm{N}$-terminal and internal amino acid sequences of S1 (Additional file 1). PCR was carried out in standard conditions for Ex Taq polymerase (TaKaRa Bio) according to the manufacturer's instructions. To isolate the full-length gene encoding S1, genomic-walking PCR was performed using a GenomeWalker Kit (TaKaRa Bio) according to the manufacturer's instructions. Nucleotide and amino acid sequences were analyzed using the BLASTn and BLASTp programs, respectively (https://blast.ncbi.nlm.nih.gov/ Blast.cgi). The Carbohydrate Active Enzymes (CAZY) server (http://afmb.cnrs-mrs.fr/pedro/CAZY) was used for determining glycosyl hydrolase and CBM families. The GenBank accession number for $S 1$ from P. curdlanolyticus B-6 is KP723173.

\section{Purification of $r S 1$, major xylanase subunit Xyn11A and its derivatives, and glycosylation detection}

The oligonucleotide primers used in this research are listed in Additional file 1. To produce the recombinant proteins $\mathrm{rS} 1$ and rSLH (Fig. 1) in E. coli, expression 
plasmids pET-S1 and pET-SLH were prepared using the $S 1$ gene from $P$. curdlanolyticus B-6. Each recombinant protein was purified with the Profinia Affinity Chromatography Protein Purification System (Bio-Rad Laboratories). Protein concentrations were determined using a Pierce BCA assay kit (Thermo Fisher Scientific, MA, USA) with bovine serum albumin as the standard. Glycoproteins were visualized by staining with a Glycoprotein Staining Kit (G-Biosciences, St. Louis, MO, USA) according to the manufacturer's instructions. After the initial staining and imaging of glycosylated proteins, the gel was counterstained with RAPID stain solution from the same kit to visualize all the proteins.

\section{Preparation of cell wall fragments of $P$. curdlanolyticus B-6} Paenibacillus curdlanolyticus B-6 cells from $500 \mathrm{ml}$ of a mid-exponential-phase culture were harvested, washed twice with $100 \mathrm{ml}$ of $50 \mathrm{mM}$ phosphate buffer ( $\mathrm{pH}$ 7.0),

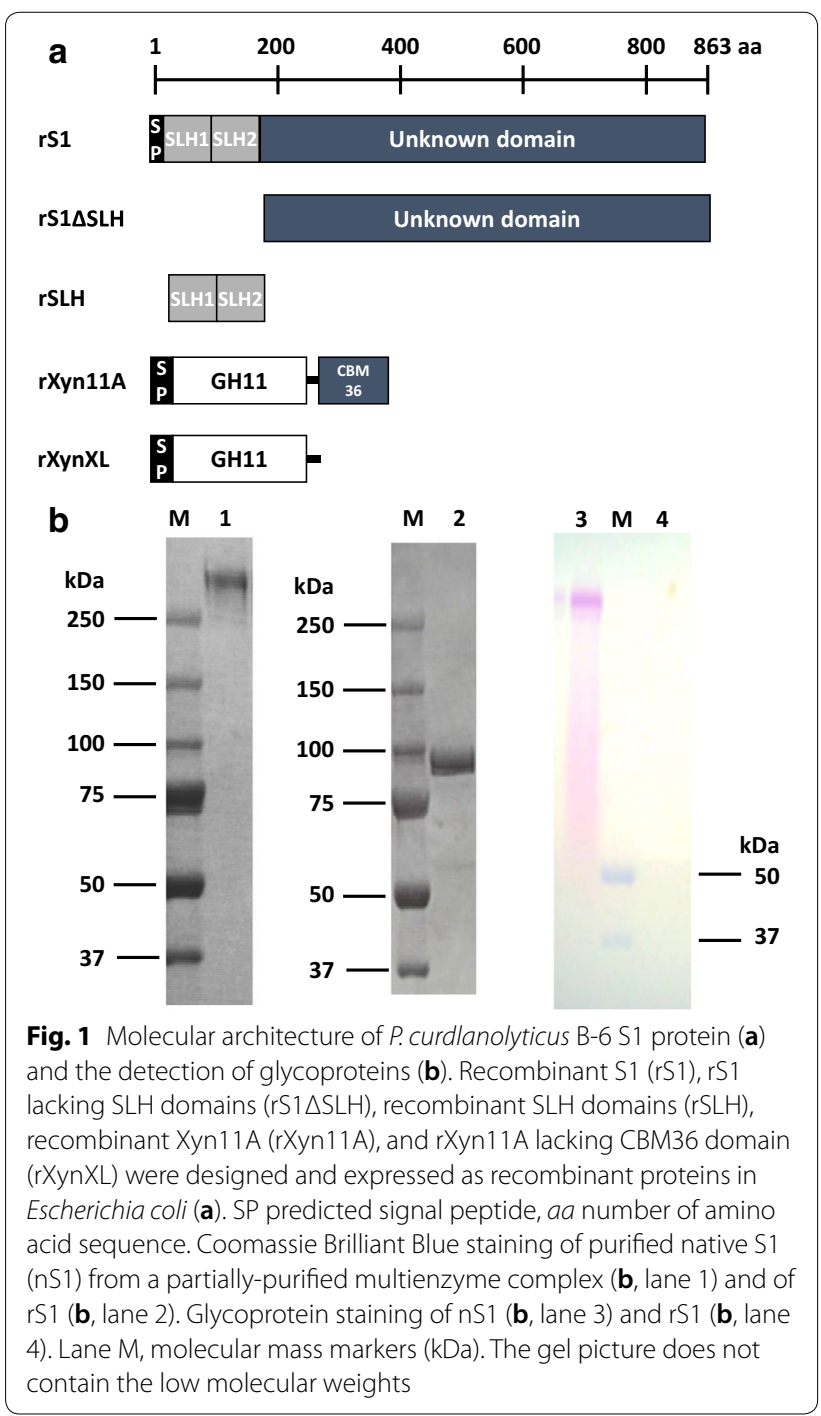

and resuspended in $10 \mathrm{ml}$ of the same buffer. The cell suspension was disrupted by sonication, intact cells were removed by centrifuging twice at $1940 \times g$ for $5 \mathrm{~min}$, and the suspensions were recentrifuged at $39,200 \times g$ for $20 \mathrm{~min}$. The pellet was suspended in $5 \mathrm{ml}$ of $50 \mathrm{mM}$ phosphate buffer ( $\mathrm{pH} 7.0)$, treated with $1 \%$ SDS by boiling in a water bath for $20 \mathrm{~min}$, and centrifuged at $16,000 \times g$ for $20 \mathrm{~min}$ at room temperature. The supernatant consisted of the cell wall-associated proteins. The pellet, consisting of the cell wall, was resuspended in $5 \mathrm{ml}$ of $50 \mathrm{mM}$ phosphate buffer ( $\mathrm{pH} 7.0)$ after being washed three times with the same buffer.

\section{Binding properties of $\mathrm{rS} 1$ toward polysaccharides and cell wall fragments}

The $\mathrm{rS} 1$ protein $(50-150 \mu \mathrm{g})$ was incubated for $4 \mathrm{~h}$ at $30{ }^{\circ} \mathrm{C}$ in $200 \mu \mathrm{l}$ of $50 \mathrm{mM}$ sodium phosphate buffer $(\mathrm{pH}$ 7.0) with the prepared cell wall fragments $(50-200 \mu \mathrm{g})$, microcrystalline cellulose (Sigmacell type 20, SigmaAldrich), acid swollen cellulose, insoluble xylan from birchwood, arabinan (Sigma-Aldrich), or chitin (SigmaAldrich) with each polysaccharide at a concentration of $10 \mathrm{mg} / \mathrm{ml}$. The reaction mixtures were incubated for $4 \mathrm{~h}$ at $30{ }^{\circ} \mathrm{C}$ with gentle shaking. The bound and free proteins were separated by centrifugation at $16,000 \times g$ for $10 \mathrm{~min}$ at room temperature. The supernatant consisted of the free protein fraction. A wash fraction was obtained after washing the pellet with $50 \mathrm{mM}$ phosphate buffer ( $\mathrm{pH}$ 7.0). The pellet, consisting of the insoluble cell wall fragments and attached proteins, was washed with the same buffer and then resuspended in $300 \mu \mathrm{l}$ of the phosphate buffer. Each fraction was analyzed by SDS-PAGE. To calculate the binding parameters for insoluble carbohydrates, the protein concentrations in the total pellet suspension and free protein were determined using a BCA protein assay kit (Thermo Fisher Scientific). The amount of bound polypeptide was calculated by subtracting the amount of free protein from the amount remaining in the pellet suspension. Affinity $\left(K_{\mathrm{d}}\right)$ and binding capacity $([P C] \max )$ parameters were calculated using double-reciprocal plots with different fixed levels of bound proteins and insoluble materials, as described previously (Pason et al. 2006).

\section{In vitro reconstruction of the complex using $\mathrm{nS} 1$}

In vitro reconstruction was carried out using rXyn11A (Pason et al. 2010), rXynXL (Sermsathanaswadi et al. 2014), rS1, and nS1 purified from the P. curdlanolyticus B-6 complex. Purified S1 (approximately $140 \mu$ g protein; $0.5 \mu \mathrm{M}$ ) was mixed with rXyn11A (approximately $20 \mu \mathrm{g}$ protein; $0.5 \mu \mathrm{M}$ ) or $\mathrm{rXynXL}$ (approximately $11 \mu \mathrm{g}$ protein; $0.5 \mu \mathrm{M}$ ) in phosphate-buffered saline containing $1 \mathrm{mM} \mathrm{CaCl}_{2}$. To compare differences in their interaction 
abilities, rS1 (approximately $46 \mu$ g protein; $0.5 \mu \mathrm{M}$ ) was also mixed with rXyn11A (approximately $20 \mu \mathrm{g}$ protein; $0.5 \mu \mathrm{M})$ in phosphate-buffered saline buffer containing $\mathrm{CaCl}_{2}$. MilliQ water (Millipore Corporation, Billerica, MA, USA) was added to a final volume of $100 \mu \mathrm{l}$. The proteins were incubated at room temperature overnight to allow complex formation. A gel-shift experiment with a non-denaturing PAGE analysis was performed. Nondenaturing sample buffer (192 mM glycine, $25 \mathrm{mM}$ Tris; Thermo Fisher Scientific) was added, and $40 \mu \mathrm{l}$ sample/lane was analyzed by PAGE using a NativePAGE ${ }^{\mathrm{TM}}$ Novex ${ }^{\circledR}$ Bis-Tris gel system according to the manufacturer's instructions (Thermo Fisher Scientific). The cathode buffer contained $1.5 \mathrm{mM}$ Bis-Tris, $5.0 \mathrm{mM}$ tricine, and 0.002\% Coomassie Brilliant Blue R-250 (w/v; pH 7.0) (Bio-Rad Laboratories), and the anode buffer contained 5.0 mM Bis-Tris (pH 7.0).

\section{Enzymatic characterization of S1 protein}

Xylanase activity was measured by determining the amount of reducing sugar released from birchwood xylan, oat-spelt xylan, and arabinoxylan (wheat flour) (Sigma-Aldrich) for $15 \mathrm{~min}$ incubation (Okada and Shinmyo 1988). Released reducing sugars were quantified using the Somogyi-Nelson method with xylose as a standard (Wood and Bhat 1988). One unit of xylanase activity was defined as the amount of enzyme that liberated $1 \mu \mathrm{mol}$ of reducing sugar in $1 \mathrm{~min}$ under the above conditions. $K_{\mathrm{m}}, V_{\max }$ and $K_{c a t}$ values for $\mathrm{rS} 1$ were determined using the Lineweaver-Burk method (Sermsathanaswadi et al. 2017).

\section{Hydrolysis of xylooligosaccharides by rS1}

rS1 was incubated in $50 \mathrm{mM}$ phosphate buffer ( $\mathrm{pH} 7.0)$ containing $1 \mathrm{mM}$ xylooligosaccharides (Megazyme International, Wicklow, Ireland) for $1 \mathrm{~h}$ at $60{ }^{\circ} \mathrm{C}$. Mono- and oligo-saccharide contents in the supernatants were measured by high-performance liquid chromatography (Shimadzu Corp., Kyoto, Japan) (Sermsathanaswadi et al. 2017). Xylan hydrolysis products were also determined by thin-layer chromatography (Sermsathanaswadi et al. 2017).

\section{Synergistic effect between nS1 and rXyn11A}

Synergistic effects were investigated by incubating aliquots $(50 \mu \mathrm{l})$ of the protein samples $(0.5 \mu \mathrm{M}$ in $50 \mathrm{mM}$ sodium phosphate buffer, $\mathrm{pH} 7.0$ ) with $3 \mathrm{ml}$ of birchwood xylan $(5 \mathrm{~g} / \mathrm{l}$ in $50 \mathrm{mM}$ sodium phosphate buffer, $\mathrm{pH}$ $7.0)$ at $60{ }^{\circ} \mathrm{C}$ with shaking at $150 \mathrm{rpm}$. Aliquots $(0.2 \mathrm{ml})$ were extracted at $0,1,2,3,5$, and $10 \mathrm{~h}$, centrifuged, and examined for soluble reducing sugars using xylose as the standard. The released sugars in supernatants were measured using the Somogyi-Nelson method.

\section{Homology modeling}

The SbsB S-layer protein of Geobacillus stearothermophilus PV72p2 (PDB accession number 4aq1) (Baranova et al. 2012) and cell wall-anchoring protein of $P$. alvei (PDB accession number 6cwc for the SLH domains) (Blackler et al. 2018) were used as the templates for the construction of a three-dimensional structural model of P. curdlanolyticus B-6 S1 in the SWISS-MODEL protein-modeling server (http://swissmodel.expasy.org/), representing the unknown and SLH domains of S1, respectively.

\section{Results}

\section{S1 from P. curdlanolyticus B-6}

To determine whether the scaffolding-like S1 protein has a structure similar to that of the cohesins that are normally observed in cellulosomes from cellulolytic clostridia, the $S 1$ gene was cloned from P. curdlanolyticus B-6. An $S 1$ gene fragment was amplified by PCR using degenerate primers based on the N-terminal amino acid sequence (AEDAQPSTQD, amino acid residues 25-34) by Edman degradation and an internal amino acid sequence in situ by proteolytic enzymes such as trypsin or staphylococcal V-8 protease (DGSIERGYAG, amino acid residues 804-815) of the protein (GenBank accession number KP723173.1). The 5'- and 3'-flanking regions were amplified by PCR-based genome walking and assembled with the known partial sequence. The full-length $S 1$ gene contains 2589 bp and encodes a protein of 863 amino acids, with a calculated molecular mass of $\sim 91 \mathrm{kDa}$. The $\mathrm{N}$-terminal region showed homology with the S-layer domain-containing hypothetical protein from Paenibacillus sp. 32O-W (50\% identity, WP_062490275.1) and Paenibacillus sp. UNC496MF (43\% identity, SFJ26475.1). However, the hypothetical scaffolding-like S1 protein has a different structure from those of known scaffolding proteins, such as CipA and CbpA in cellulosomes (Bayer et al. 2004; Doi and Kosugi 2004; Lynd et al. 2002). According to a BLAST analysis, the first 125 amino acids of S1 were identified as two surface-layer homology (SLH) domain sequences (Fig. 1a). SLH1 (amino acids 24 to 65) and SLH2 (amino acids 82 to 125) had high homology levels with an S-layer domain protein from Geobacillus sp. Y412MC10 (69\% identity, ZP_03037712) and Paenibacillus sp. oral taxon 786 str. D14 (52\% identity, ZP_04851624), respectively. We could find no functional similarities to the amino acid sequences following the SLH domains (i.e., from residues 126 to 763 ) in any databases, including GenBank, EMBL, and DDBJ.

There were four inconsistencies between our sequence analysis and the protein properties of S1 characterized in previous reports (Pason et al. 2006, 2010), as follows: 
(1) the theoretical mass of the S1 protein based on the sequence $(\sim 91 \mathrm{kDa})$ is quite different from the $\sim 280-\mathrm{kDa}$ molecular mass determined by SDS-PAGE of native S1 (nS1); (2) in general, cohesin-dockerin modules are necessary for interactions between a scaffolding protein and enzymatic subunits in known multienzyme complexes such as the cellulosome (Doi and Kosugi 2004), but these modules are not present in the S1 protein sequence. Nevertheless, a multienzyme complex prepared from $P$. curdlanolyticus B-6 is tightly assembled from $\mathrm{nS} 1$, major xylanase (Xyn11A), and several minor cellulases and xylanases; (3) when a zymogram analysis of this multienzyme complex was carried out with birchwood xylan as the substrate, the xylan degradation ability was clearly observed at $\sim 280 \mathrm{kDa}$, corresponding to the size of $\mathrm{nS} 1$; (4) the enzyme complex of P. curdlanolyticus B-6 can bind microcrystalline cellulose even though there is no clear $\mathrm{CBM}$ in the S1 protein sequence. To understand these inconsistencies, the $\mathrm{nS} 1$ protein, recombinant $\mathrm{S} 1$ (rS1) protein, some derivatives, and Xyn11A (Fig. 1a), as the major associated enzyme subunit, were analyzed.

\section{Different molecular masses of $\mathrm{nS} 1$ and $\mathrm{rS} 1$}

The $\mathrm{nS} 1$ protein was partially prepared from a culture supernatant of P. curdlanolyticus B-6 using ammonium sulfate precipitation and ion and hydrophobic interaction chromatography (Pason et al. 2010). The molecular masses of the purified $\mathrm{nS} 1$ and $\mathrm{rS} 1$ from Escherichia coli were compared by SDS-PAGE (Fig. 1b). The molecular mass of nS1 was $\sim 280 \mathrm{kDa}$, compared with $\sim 91 \mathrm{kDa}$ for $\mathrm{rS} 1$. An analysis using a glycoprotein staining kit revealed that this difference in molecular mass resulted from the glycosylation of nS1. rS1 was not glycosylated (Fig. 1b).

\section{Complex formation with recombinant Xyn11A}

To confirm whether the S1 protein can play the role of a scaffolding protein that interacts with enzyme subunits in a multienzyme complex, analogous to the cellulosome, interaction tests were carried out using $\mathrm{nS} 1$ or $\mathrm{rS} 1$ as the scaffolding protein and rXyn11A. Xyn11A, consisting of a glycosyl hydrolase family $(\mathrm{GH}) 11$ xylanase catalytic domains, a linker sequence, and a family 36 CBM, was characterized as the major xylanase in the multienzyme complex from P. curdlanolyticus B-6 (Pason et al. 2010; Sermsathanaswadi et al. 2014). However, Xyn11A does not have any modules, such as dockerin, that are necessary for the interactions of enzymes with scaffolding proteins in the cellulosome.

A blue native polyacrylamide gel was used to investigate the interactions between S1s and rXyn11A. Incubating $\mathrm{rS} 1$ with $\mathrm{rXyn} 11 \mathrm{~A}$ did not result in any observed interactions (Fig. 2a). In contrast, $\mathrm{nS} 1$ and $\mathrm{rXyn} 11 \mathrm{~A}$ interacted, migrating at a greater molecular mass than each individual protein (Fig. 2b). Thus, the glycosylation of $\mathrm{nS} 1$ may be important for the interaction of S1 with Xyn11A, at least in multienzyme complex formation. Thus, to test whether the CBM of rXyn11A bound to glycosyl chains of $\mathrm{nS} 1, \mathrm{nS} 1$ was incubated with rXynXL (Fig. 1a), a form of Xyn11A from which the family 36 CBM was removed (Sermsathanaswadi et al. 2014). nS1 could interact with rXynXL (Fig. 2c), but the interaction appeared weaker than that between $\mathrm{nS} 1$ and intact rXyn11A. Thus, CBMs in enzyme subunits might contribute to the assembly of the P. curdlanolyticus B-6 multienzyme complex through weak binding to the glycosyl side chains of S1.

\section{Xylan degradation properties of S1}

No GH family catalytic domains are predicted in S1 based on its sequence. Nevertheless, a xylan hydrolysis ability of $\mathrm{nS} 1$ was seen when the partially purified multienzyme complex was applied to a zymogram analysis in which birchwood xylan was the substrate (Pason et al. 2010). To determine whether $S 1$ has a xylan degradation ability, the hydrolytic abilities of $\mathrm{nS} 1$ and $\mathrm{rS} 1$ were characterized for xylan and other substrates having glycosidic bonds. nS1 and rS1 had clear hydrolytic abilities toward

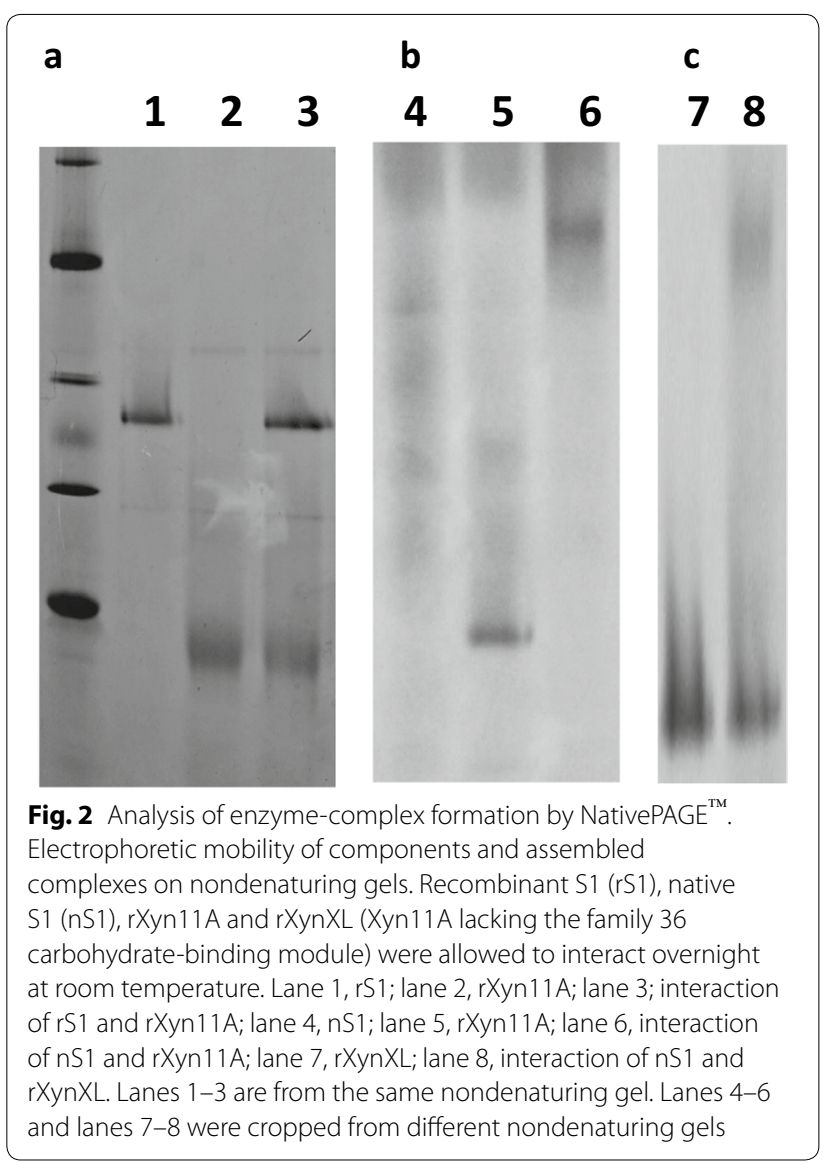


soluble and insoluble birchwood xylan, but no activities toward microcrystalline cellulose, CMC, $\beta$-glucan, starch, arabinan, xyloglucan, chitin, or $p$-nitrophenol substrates (Additional file 2). The xylan degradation activities of $\mathrm{nS} 1$ were $0.69 \pm 0.05$ and $0.38 \pm 0.04 \mathrm{U} / \mathrm{mg}$ protein toward soluble and insoluble birchwood xylan, respectively, while the activities of $\mathrm{rS} 1$ were $0.55 \pm 0.02$ and $0.36 \pm 0.01 \mathrm{U} / \mathrm{mg}$ protein, respectively. Thus, the glycosylation of S1 may not influence the xylan degradation ability.

The xylanase activity of $\mathrm{nS} 1$ decreased by $80 \%$ with the addition of $1 \mathrm{mM}$ ethylenediaminetetraacetic acid, and the presence of divalent cations $\left(1 \mathrm{mM} \mathrm{Ca}^{2+}\right.$ or $\mathrm{Mg}^{2+}$ ) enhanced the xylanase activity, indicating that the protein may contain a $\mathrm{Ca}^{2+}$-binding site that is functionally important (Additional file 3). Kinetic parameters were determined for $\mathrm{nS} 1$ and $\mathrm{rS1}$ using soluble birchwood xylan as the substrate (Table 1). rXyn11A has high $K_{m}$ and $K_{c a t}$ (Sermsathanaswadi et al. 2014) values compared with those of S1. nS1 showed lower kinetic parameters than that of rS1 (Table 1), however, similar optimum reaction $\mathrm{pH}$ levels $\left(\mathrm{pH}\right.$ 6.0) and temperatures $\left(60^{\circ} \mathrm{C}\right)$, for xylan degradation. When rS1 was incubated with xylooligosaccharides, such as xylotetraose, xylopentaose, and xylohexaose, and birchwood xylan, the major products were xylotetraose and xylotriose; however, $\mathrm{nS} 1$ and $\mathrm{rS} 1$ cannot degrade to xylose (Fig. 3a, b).

\section{Carbohydrate binding ability of S1}

The multienzyme complex was prepared from a culture supernatant of $P$. curdlanolyticus B- 6 using a combination of cellulose-binding affinity and several column chromatographic steps (Pason et al. 2006, 2010). To determine whether the $\mathrm{S} 1$ protein could bind to cellulose and other polysaccharides, binding properties and affinities were characterized using rS1. rS1 could bind to microcrystalline cellulose (Fig. 4a), insoluble xylan, and chitin, but not to acid swollen cellulose or arabinan (Fig. 4b). To determine which regions of the protein are responsible for carbohydrate binding, binding experiments with microcrystalline cellulose were carried out using recombinant S1 with the SLH1 and 2 domains removed (rS1 $\Delta$ SLH)

Table 1 Enzymatic characterization of nS1, rS1 and rXyn11A

\begin{tabular}{|c|c|c|c|}
\hline Property & $\mathrm{nS1}$ & rS1 & rXyn11A \\
\hline Molecular mass (kDa) & 280 & 91 & 40 \\
\hline Structure & SLH-unknown glycoprotein & SLH-unknown & GH11-linker-CBM36 \\
\hline Temperature optimum (stability) & $60^{\circ} \mathrm{C}\left(<60^{\circ} \mathrm{C}\right)$ & $60^{\circ} \mathrm{C}\left(<60^{\circ} \mathrm{C}\right)$ & $60^{\circ} \mathrm{C}$ \\
\hline pH optimum (stability) & $6.0(6.0-8.0)$ & $6.0(6.0-8.0)$ & $6.0(6.0-7.0)$ \\
\hline$K_{m}(\mathrm{mg} / \mathrm{ml})$ & $29.5 \pm 2.0$ & $19.5 \pm 3.0$ & $1.5 \pm 0.1$ \\
\hline$K_{\text {cat }}(1 / s)$ & $66.1 \pm 0.1$ & $162.2 \pm 2.0$ & $204.4 \pm 3.0$ \\
\hline
\end{tabular}

Soluble birchwood xylan was used as substrate

Data are presented as the means from three independent experiments. Errors represent standard deviations $(n=3)$

SLH surface layer homology domain, GH11 glycosyl hydrolase family 11, CBM36 family 36 carbohydrate-binding module
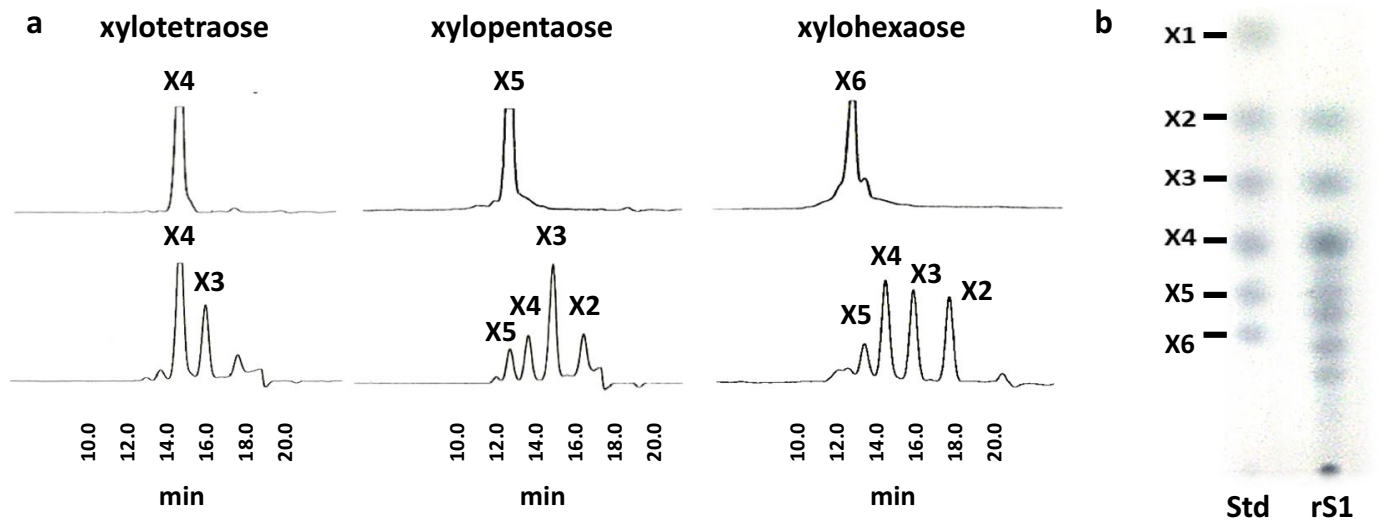

Fig. 3 End-product analysis of xylooligosaccharides and xylan hydrolyzed by rS1. The end products were analyzed by high-performance liquid chromatography (a). Thin-layer chromatography of hydrolysis products of soluble birchwood xylan (b). Authentic xylooligosaccharides were used as standards (lane Std). X1, xylose; X2 to X6, xylobiose to xylohexaose 
and with the SLH1 and 2 domains of S1 only (rSLH). When $\mathrm{rS} 1 \triangle \mathrm{SLH}$ and $\mathrm{rSLH}$ were respectively incubated with microcrystalline cellulose, $\mathrm{rS} 1 \Delta \mathrm{SLH}$ lost the cellulose-binding ability, while rSLH could bind to cellulose (Fig. 4a), indicating that the SLH domains are responsible for binding to cellulose.

The SLH domain functions in anchoring to the cell surface of Gram-positive bacteria by binding to the peptidoglycan layer (PGL) (Blackler et al. 2018; Sára and Sleytr 2000). To determine whether the SLH domains of S1 can also play an anchoring role to this cell surface layer, binding tests were carried out using a PGL prepared from $P$. curdlanolyticus B-6. Although $\mathrm{rS} 1$ and $\mathrm{rSLH}$ could bind to the PGL, rS1 $\triangle$ SLH remained in the unbound fraction. Thus, the SLH domains of S1 are bifunctional, binding to the cell surface of $P$. curdlanolyticus B-6 and to microcrystalline cellulose (Fig. 4c). To compare binding properties, the binding affinities of the SLH domains were measured with the PGL, cellulose, and insoluble xylan. $\mathrm{rS} 1$ showed a greater binding affinity and lower capacity for the PGL $(0.10 \pm 0.01 \mu \mathrm{M}$ and $0.19 \pm 0.01 \mu \mathrm{mol} / \mathrm{g}$, respectively) than for cellulose $(0.23 \pm 0.02 \mu \mathrm{M}$ and $0.27 \pm 0.01 \mu \mathrm{mol} / \mathrm{g}$, respectively) or insoluble xylan $(0.22 \pm 0.01 \mu \mathrm{M}$ and $0.24 \pm 0.01 \mu \mathrm{mol} / \mathrm{g}$, respectively) (Table 2). rS1 $\Delta$ SLH lost the ability to bind the PGL and microcrystalline cellulose, but could still bind insoluble xylan (Table 2). Thus, the SLH domains appear to mainly act in cell surface anchoring, while the multienzyme complex involving S1 dissociated from the cell surface may bind to substrates, such as cellulose and xylan, through the SLH domains.

\section{Synergistic xylan degradation of enzyme complex containing $\mathrm{S} 1$ and $\mathrm{rXyn} 11 \mathrm{~A}$}

Cellulosome components (the scaffolding protein and enzyme subunits) show synergistic degradation effects when associated with the substrate (Bayer et al. 2004, 2008). To test whether S1 is also able to cooperate in a complex with synergistic effects, experiments were

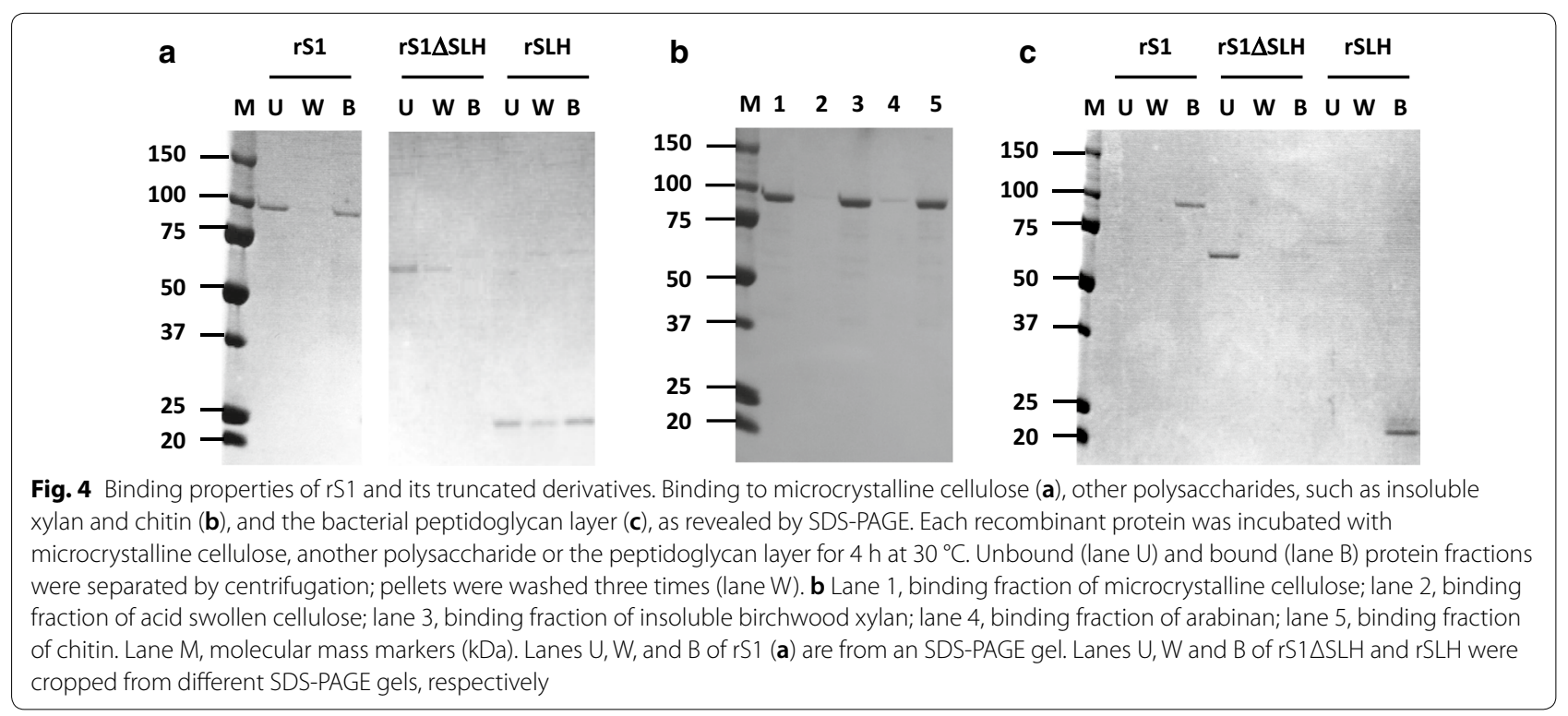

Table 2 Binding affinities and capacities of rS1 and its truncated derivatives toward the peptidoglycan cell surface layer and insoluble substrates

\begin{tabular}{|c|c|c|c|c|c|c|}
\hline \multirow[t]{2}{*}{ Substrates } & \multicolumn{3}{|l|}{$K_{\mathrm{d}}(\mu \mathrm{M})^{\mathrm{a}}$} & \multicolumn{3}{|c|}{$[P C] \max (\mu \mathrm{mol} / \mathrm{g} \text { substrate })^{\mathrm{a}}$} \\
\hline & rS1 & $\mathrm{rS} 1 \Delta \mathrm{SLH}$ & rSLH & rS1 & $\mathrm{rS} 1 \Delta \mathrm{SLH}$ & rSLH \\
\hline Peptidoglycan layer & $0.10 \pm 0.05$ & $N D^{b}$ & $0.12 \pm 0.04$ & $0.19 \pm 0.1$ & ND & $0.15 \pm 0.1$ \\
\hline Microcrystalline cellulose & $0.23 \pm 0.05$ & ND & $0.27 \pm 0.05$ & $0.27 \pm 0.1$ & ND & $0.23 \pm 0.1$ \\
\hline Insoluble xylan & $0.22 \pm 0.04$ & $1.32 \pm 0.2$ & $0.32 \pm 0.03$ & $0.24 \pm 0.1$ & $0.20 \pm 0.04$ & $0.20 \pm 0.1$ \\
\hline
\end{tabular}

Data are presented as the means from three independent experiments. Error bars represent the standard deviation $(n=3)$

a The binding assay was performed in triplicate, and the $K_{\mathrm{d}}$ and $[P C]$ max values were calculated by using a double-reciprocal plot

b ND, no binding detected 
performed with nS1 and rXyn11A using insoluble birchwood xylan as the substrate. The xylan-degrading abilities of $\mathrm{nS} 1(0.5 \mu \mathrm{M})$ and $\mathrm{rXyn} 11 \mathrm{~A}(0.5 \mu \mathrm{M})$ individually were $27 \mu \mathrm{g} / \mathrm{ml}$ and $71.0 \mu \mathrm{g} / \mathrm{ml}$ released reducing sugars, respectively (Fig. 5). When $\mathrm{nS} 1$ and rXyn11A were incubated together with xylan, the degradation ability was enhanced, to $223 \mu \mathrm{g} / \mathrm{ml}$ released reducing sugar. Thus, the complex had a synergistic xylan-degradation effect. However, synergistic effects were not observed for a mixture of rS1 and rXyn11A (Fig. 5). Thus, S1 may play a scaffolding protein-like role and assemble enzyme subunits. In addition, the glycosylation of S1 is important for the assembly of scaffold subunits.

\section{Discussion}

In this study, the roles of S1, a scaffolding-like protein in a multienzyme complex produced by $P$. curdlanolyticus B-6, in enzyme-complex formation and xylan degradation were characterized. We identified four inconsistencies between the sequence analysis of $\mathrm{S} 1$ and the protein properties of S1 reported previously (Pason et al. 2010). Based on the sequence analysis, the molecular mass of $\mathrm{S} 1$ was predicted to be $\sim 91 \mathrm{kDa}$, compared with an observed value of $\sim 280 \mathrm{kDa}$ for $\mathrm{nS} 1$. This difference was the result of glycosylation. As a similar example, the scaffolding protein CipA of the C. thermocellum cellulosome is also heavily glycosylated by carbohydrate chains based on galactose and glucose (Demain et al. 2005; Mori 1992). Reported prokaryotic glycoproteins are classified into five major types depending upon their localization and include surface layer glycoproteins, membrane associated glycoproteins, cell-surface glycoproteins, secreted glycoproteins, and exo-enzymes (Upreti et al. 2003). The

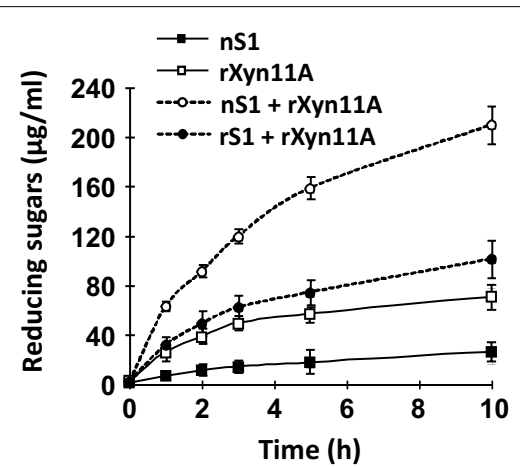

Fig. 5 Hydrolysis activity profiles. The enzymatic activities of nS1, rXYn11A, the nS1 plus rXyn11A complex, and the rS1 plus rXyn11A complex toward birchwood xylan were independently determined by measuring the amount of reducing sugar released from $0.5 \%$ substrate at $60^{\circ} \mathrm{C}$. The complexes were assembled by mixing $\mathrm{nS} 1$ or rS1 with rXyn11A at fixed concentrations $(0.5 \mu \mathrm{M})$. Data are presented as the means from three independent experiments. Error bars represent the standard deviations $(n=3)$ glycosylation of proteins may enhance their hydrophilic properties and aggregation capabilities in the presence of divalent cations (Paul and Wieland 1987), suggesting that protein-protein interactions through cations may be involved the properties. The glycosylation of S1 plays an important role in assembling the multienzyme complex of $P$. curdlanolyticus B-6, because no complex was formed by (unglycosylated) $\mathrm{rS} 1$. $N$-linked glycosylation usually occurs at the Asn of Asn-X-Ser/Thr sequences (J Lechner and Wieland 1989; Upreti et al. 2003), and such motifs are located starting at positions $58,73,118,318$, 695,831 , and 852 of the S1 amino acid sequence. Prediction software (NetNGlyc 1.0; http://www.cbs.dtu.dk/ services/NetNGlyc/) suggested that positions $58,73,118$, and 318 may be $N$-glycosylated, and three of these positions $(58,73$, and 118) are located in the SLH domains. An analysis of the chemical components of $\mathrm{nS} 1$ is necessary to help elucidate the mechanism(s) of protein-protein interactions occurring through the glycosyl chains.

However, the glycosylation of S1 did not appear to play any role in its enzyme activity. We observed that $\mathrm{nS} 1$ and rS1 showed similar enzymatic properties, kinetic parameters, and xylan-degradation capacities (Table 1). There are no protein regions with homology to any known GH families, and the 738 amino acids after the SLH domains shows no functional homology with any sequence in any public database. The $\beta-1,4-x y l a n a s e s$ are generally included in GH10 and GH11 based on primary structure similarity and three-dimensional structural homology levels. GH11 xylanases are highly specific, displaying exclusive substrate specificity toward xylose-containing substrates and a preference for insoluble polymeric substrates. S1 shows a high substrate specificity toward xylan (Additional file 2); however, the enzymatic affinity and capacity are remarkably low compared with those of rXyn11A (Table 1). The GH11 proteins contain a single major $\alpha$-helix and two extended pleated $\beta$-sheets that form a jelly-roll fold (Paës et al. 2012). The structural features include a compact globular structure and a thumb-like structure as an 11-residue loop that contains the active site (Paës et al. 2012; Wakarchuk et al. 1994). When S1 was analyzed by three-dimensional structural modeling based on the SbsB S-layer protein from $G$. stearothermophilus (PDB code 4aq1.2), as the most similar protein (69.5\% amino acid similarity), an immunoglobulin-like fold (Baranova et al. 2012) was observed in the modeled structure (Fig. 6a). The catalytic machinery of GH11 is composed of two glutamate residues, acting as a nucleophile and an acid/base catalyst, respectively, located in the middle of the long cleft (Paës et al. 2012). Although 46 glutamate residues and many $\beta$-strand structures were observed in the model of $\mathrm{S} 1$, a cleft that spans the entire molecule could not clearly be identified. 
Thus, additional experiments, such as three-dimensional structure and domain function analysis, are necessary to determine whether S1 contains a novel type of catalytic domain.

SLHs of Gram-positive bacteria generally have covalently bound carbohydrate chains. However, as far as we know, the carbohydrate-binding ability of the SLH domain has not been reported. Typically, S-layer proteins have a high acidic and hydrophobic amino acid contents. The SLH domains of S1 also contained many hydrophobic amino acids, including 1, 2.5, and $4.5 \mathrm{~mol} \%$ tryptophan, tyrosine, and phenylalanine, respectively. This ratio is similar to that of the novel proposed CBM region of the mature CttA protein (0.78, 3.66, and $2.62 \mathrm{~mol} \%$ tryptophan, tyrosine, and phenylalanine, respectively) (Rincon et al. 2007). CBMs have been extensively characterized in CAZY database (http://www.cazy.org/) and grouped into three types reflecting both their mode of ligand recognition and the substrate of glycan (Boraston et al. 2004). Type A CBMs bind to the surface of crystalline polysaccharides, type $B$ proteins interact with internal regions of single glycan chains (endo-type), and type $\mathrm{C}$ modules recognize the termini of glycan chains (exo-type) (Boraston et al. 2004; Gilbert et al. 2013). Type A CBMs use a flat surface populated with aromatic residues to bind to crystalline cellulose, whereas type B CBMs use a deep groove to bind individual twisted glucan chains found in disordered cellulose (Boraston et al. 2004). A modeling result based on SLH domains from P. alvei (SWISS-MODEL: 6cwc.1) (Blackler et al. 2018) showed structures with three helices, quite different from known type A and B CBM structures (Fig. 6b). It

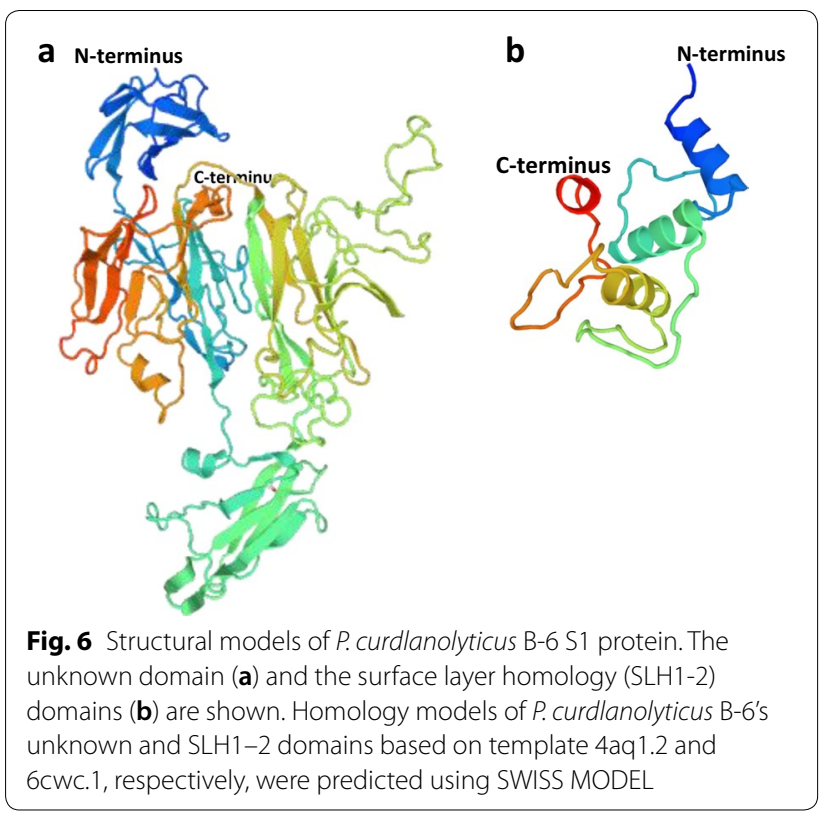

is unknown whether the aromatic residues of SLH play an important role in cellulose and xylan binding. Thus, molecular research, such as replacement of the aromatic residues, is necessary to obtain a further understanding of the SLH domains' affinities for cellulose and xylan.

Efficient cellulose degradation by C. thermocellum is essentially dependent on the formation of the cellulosome complex, mediated by the primary scaffoldin protein CipA (Bayer et al. 2004, 2008). Nevertheless, examples of other protein-protein assemblies include a unique mechanism of carbohydrate gluing to yield the complete quaternary supramolecular structure of an annelid giant hemoglobin (Ebina et al. 1995), in which carbohydrate acts noncovalently to glue together the components. In addition, glycosyl hydrolase subunits with CBMs might be able to bind to glycosyl side chains of glycoproteins. It is not clear whether carbohydrate gluing and/or CBM-equipped subunits are involved in the assembly of the P. curdlanolyticus B-6 multienzyme complex. However, glycosyl side chains of S1 may be important in the formation of the supramolecular complex because non-glycosylated S1 (i.e., rS1) lost the ability to assemble this complex. When $\mathrm{nS} 1$ and rXyn11A were incubated with xylan, synergistic xylan-degradation effects were observed. Similarly, the degradation of crystalline cellulose was reportedly increased by adding the scaffolding protein CipA to the cellulosomal subunits (Fierobe et al. 2002; Hirano et al. 2015). Thus, our results indicate that $\mathrm{nS} 1$ may have a scaffolding-like function, even though the multienzyme complex produced by $P$. curdlanolyticus B-6 uses a different manner of assembly from that of the cellulosome. According to a BLAST analysis, S1-like proteins containing S-layer domains are found in several Paenibacillus species, such as P. beijingensis, and Paenibacillus sp. 32O-W, even though they share low amino acid sequence identities $(40-42 \%)$. This is the first report to functionally characterize the hypothetical surface layer-protein S1. A further characterization of S1 may reveal novel protein-protein interactions and a novel GH family.

\section{Supplementary information}

Supplementary information accompanies this paper at https://doi. org/10.1186/s13568-019-0896-0.

Additional file 1. Oligonucleotide primers used for S1 gene cloning and construction of $\mathrm{rS} 1$ and its truncated derivatives.

Additional file 2. Substrate specificity of nS1 and rS1.

Additional file 3 . Effects of cations and chelating reagents on the xylanase activity of nS1. 


\section{Abbreviations}

CMC: carboxymethyl cellulose; SLH: surface layer homology; rSLH: recombinant SLH; nS1: native S1; rS1: recombinant S1; rXyn11A: recombinant Xyn11A; CBM: carbohydrate-binding module; SDS-PAGE: sodium dodecyl sulfate-polyacrylamide gel electrophoresis; $\mathrm{GH}$ : glycosyl hydrolase family; PGL: peptidoglycan layer

\section{Acknowledgements}

The authors thank the Higher Education Research Promotion and National Research University Projects of Thailand for financial support in Thailand. P. Pason would like to thank for financial support by the Royal Golden Jubilee Ph.D. program of the Thailand Research Fund (TRG5580016) and King Mongkut's University of Technology Thonburi (KMUTT). J. Sermsathanaswadi acknowledges the financial support given by Suan Dusit University. We thank James Allen, DPhil, from Edanz Group (www.edanzediting.com/ac) for editing a draft of this manuscript.

\section{Authors' contributions}

PP, JS, CT, KR and AK conceived the study and designed the experiments. PP performed all experiments. PP, JS, RW and SB prepared all the proteins for the experiments. PP, and JS performed protein modeling analysis. PP, CT, RW, $\mathrm{KR}$ and AK analyzed the data and wrote the manuscript. All authors read and approved the final manuscript.

\section{Funding}

This work was conducted as part of a development project funded by Exploratory Research for Advanced Technology (ERATO) (Grant number JPMJER1502) of the Japan Science and Technology Agency (JST), the Science and Technology Research Partnership for Sustainable Development (SATREPS), JST/ Japan International Cooperation Agency (JICA), and Thailand Research Fund (TRG5580016), and KMUTT 55th Anniversary Commemorative Fund of King Mongkut's University of Technology Thonburi (KMUTT).

\section{Availability of data and materials}

The datasets used and/or analyzed for the current study are available from the corresponding author upon reasonable request.

\section{Ethics approval and consent to participate} Not applicable.

\section{Consent for publication}

Not applicable.

\section{Competing interests}

The authors declare that they have no competing interests.

\section{Author details}

${ }^{1}$ Pilot Plant Development and Training Institute (PDTI), King Mongkut's University of Technology Thonburi (KMUTT), Bangkok 10150, Thailand. ${ }^{2}$ Department of Chemical Technology, Faculty of Science and Technology, Suan Dusit University, 295 Rajasrima Road, Dusit, Bangkok 10300, Thailand. ${ }^{3}$ School of Bioresources and Technology, King Mongkut's University of Technology Thonburi (KMUTT), Bangkuntien, Bangkok 10150, Thailand. ${ }^{4}$ Biological Resources and Post-harvest Division, Japan International Research Center for Agricultural Sciences (JIRCAS), 1-1 Ohwashi, Tsukuba, Ibaraki 305-8686, Japan.

\section{Received: 8 Auqust 2019 Accepted: 15 October 2019}

\section{Published online: 31 October 2019}

\section{References}

Baranova E, Fronzes R, Garcia-Pino A, Van Gerven N, Papapostolou D, PéhauArnaudet G, Pardon E, Steyaert J, Howorka S, Remaut H (2012) SbsB structure and lattice reconstruction unveil $\mathrm{Ca}^{2+}$ triggered S-layer assembly. Nature 487:119. https://doi.org/10.1038/nature11155

Bayer EA, Belaich J-P, Shoham Y, Lamed R (2004) The cellulosomes: multienzyme machines for degradation of plant cell wall polysaccharides. Annu Rev Microbiol 58(1):521-554. https://doi.org/10.1146/annurev.micro 57.030502 .091022
Bayer EA, Lamed R, White BA, Flint HJ (2008) From cellulosomes to cellulosomics. Chem Rec 8(6):364-377. https://doi.org/10.1002/tcr.20160

Blackler RJ, López-Guzmán A, Hager FF, Janesch B, Martinz G, Gagnon SML, Haji-Ghassemi O, Kosma P, Messner P, Schäffer C, Evans SV (2018) Structural basis of cell wall anchoring by SLH domains in Paenibacillus alvei. Nat Commun 9(1):3120. https://doi.org/10.1038/s41467-018-05471-3

Boraston AB, Bolam David N, Gilbert Harry J, Davies Gideon J (2004) Carbohydrate-binding modules: fine-tuning polysaccharide recognition. Biochem J 382(Pt 3):769-781. https://doi.org/10.1042/BJ20040892

Caffall KH, Mohnen D (2009) The structure, function, and biosynthesis of plant cell wall pectic polysaccharides. Carbohydr Res 344(14):1879-1900. https ://doi.org/10.1016/j.carres.2009.05.021

Demain AL, Newcomb M, Wu JHD (2005) Cellulase, clostridia, and ethanol. Microbiol Mol Biol Rev 69(1):124-154. https://doi.org/10.1128/ MMBR.69.1.124-154.2005

Doi RH, Kosugi A (2004) Cellulosomes: plant-cell-wall-degrading enzyme complexes. Nat Rev Microbiol 2(7):541-551. https://doi.org/10.1038/ nrmicro925

Ebina S, Matsubara K, Nagayama K, Yamaki M, Gotoh T (1995) Carbohydrate gluing, an architectural mechanism in the supramolecular structure of an annelid giant hemoglobin. Proc Natl Acad Sci USA 92(16):7367-7371

Fierobe H-P, Bayer EA, Tardif C, Czjzek M, Mechaly A, Béläich A, Lamed R, Shoham Y, Bélaiich J-P (2002) Degradation of cellulose substrates by cellulosome chimeras: substrate targeting versus proximity of enzyme components. J Biol Chem 277(51):49621-49630. https://doi.org/10.1074/ jbc.M207672200

Gilbert HJ, Knox JP, Boraston AB (2013) Advances in understanding the molecular basis of plant cell wall polysaccharide recognition by carbohydrate-binding modules. Curr Opin Struct Biol 23(5):669-677. https://doi. org/10.1016/j.sbi.2013.05.005

Hirano K, Nihei S, Hasegawa H, Haruki M, Hirano N (2015) Stoichiometric assembly of the cellulosome generates maximum synergy for the degradation of crystalline cellulose, as revealed by in vitro reconstitution of the Clostridium thermocellum cellulosome. Appl Environ Microbiol 81(14):4756-4766. https://doi.org/10.1128/aem.00772-15

Lechner J, Wieland F (1989) Structure and biosynthesis of prokaryotic glycoproteins. Annu Rev Biochem 58(1):173-194. https://doi.org/10.1146/ annurev.bi.58.070189.001133

Lynd LR, Weimer PJ, van ZyI WH, Pretorius IS (2002) Microbial cellulose utilization: fundamentals and biotechnology. Microbiol Mol Biol Rev 66(3):506-577. https://doi.org/10.1128/MMBR.66.3.506-577.2002

Mori Y (1992) Purification and characterization of an endoglucanase from the cellulosomes (multicomponent cellulase complexes) of Clostridium thermocellum. Biosci Biotechnol Biochem 56(8):1198-1203. https://doi. org/10.1271/bbb.56.1198

Okada H, Shinmyo A (1988) Xylanase of Bacillus pumilus. In: Wood WA, Kellogg ST (eds) Methods in enzymology, vol 160. Academic Press, Amsterdam, pp 632-637

Paës G, Berrin J-G, Beaugrand J (2012) GH11 xylanases: structure/function/ properties relationships and applications. Biotechnol Adv 30(3):564-592. https://doi.org/10.1016/j.biotechadv.2011.10.003

Pason P, Kyu KL, Ratanakhanokchai K (2006) Paenibacillus curdlanolyticus strain B-6 xylanolytic-cellulolytic enzyme system that degrades insoluble polysaccharides. Appl Environ Microbiol 72(4):2483-2490. https://doi. org/10.1128/aem.72.4.2483-2490.2006

Pason P, Kosugi A, Waeonukul R, Tachaapaikoon C, Ratanakhanokchai K, Arai T, Murata Y, Nakajima J, Mori Y (2010) Purification and characterization of a multienzyme complex produced by Paenibacillus curdlanolyticus B-6. Appl Microbiol Biotechnol 85(3):573-580. https://doi.org/10.1007/s0025 3-009-2117-2

Paul G, Wieland F (1987) Sequence of the halobacterial glycosaminoglycan. J Biol Chem 262(20):9587-9593

Pauly M, Keegstra K (2010) Plant cell wall polymers as precursors for biofuels. Curr Opin Plant Biol 13(3):304-311. https://doi.org/10.1016/j. pbi.2009.12.009

Rincon MT, Cepeljnik T, Martin JC, Barak Y, Lamed R, Bayer EA, Flint HJ (2007) A novel cell surface-anchored cellulose-binding protein encoded by the sca gene cluster of Ruminococcus flavefaciens. J Bacteriol 189(13):47744783. https://doi.org/10.1128/jb.00143-07

Saha B (2003) Hemicellulose bioconversion. J Ind Microbiol Biotechnol 30(5):279-291. https://doi.org/10.1007/s10295-003-0049-x 
Sára M, Sleytr UB (2000) S-Layer proteins. J Bacteriol 182(4):859

Sermsathanaswadi J, Pianwanit S, Pason P, Waeonukul R, Tachaapaikoon C, Ratanakhanokchai K, Septiningrum K, Kosugi A (2014) The C-terminal region of xylanase domain in Xyn11A from Paenibacillus curdlanolyticus B-6 plays an important role in structural stability. Appl Microbiol Biotechnol 98(19):8223-8233. https://doi.org/10.1007/s00253-014-5748-x Sermsathanaswadi J, Baramee S, Tachaapaikoon C, Pason P, Ratanakhanokchai K, Kosugi A (2017) The family 22 carbohydrate-binding module of bifunctional xylanase/ $\beta$-glucanase Xyn10E from Paenibacillus curdlanolyticus B-6 has an important role in lignocellulose degradation. Enzyme Microb Technol 96:75-84. https://doi.org/10.1016/j.enzmictec.2016.09.015

Upreti RK, Kumar M, Shankar V (2003) Bacterial glycoproteins: functions, biosynthesis and applications. Proteomics 3(4):363-379. https://doi. org/10.1002/pmic.200390052
Wakarchuk WW, Campbell RL, Sung WL, Davoodi J, Yaguchi M (1994) Mutational and crystallographic analyses of the active site residues of the Bacillus circulans xylanase. Protein Sci 3(3):467-475. https://doi. org/10.1002/pro.5560030312

Wood TM, Bhat KM (1988) Methods for measuring cellulase activities. In: Wood WA, Kellogg ST (eds) Methods in enzymology, vol 160. Academic Press, Amsterdam, pp 87-112

\section{Publisher's Note}

Springer Nature remains neutral with regard to jurisdictional claims in published maps and institutional affiliations.

\section{Submit your manuscript to a SpringerOpen ${ }^{\circ}$ journal and benefit from:}

- Convenient online submission

- Rigorous peer review

- Open access: articles freely available online

- High visibility within the field

- Retaining the copyright to your article

Submit your next manuscript at $\boldsymbol{\nabla}$ springeropen.com 